\title{
Cognitive, emotional, and social functioning of preschoolers with attention deficit hyperactivity problems
}

\author{
Guido Biele ${ }^{1 *}$, Kristin R. Overgaard² ${ }^{2}$ Svein Friis², Pal Zeiner ${ }^{2}$ and Heidi Aase ${ }^{1}$
}

\begin{abstract}
Background: Attention Deficit Hyperactivity Disorder (ADHD) is associated with deficits in different functional domains. It remains unclear if deficits in different domains are equally strong in early childhood, and which deficits are specific to ADHD. Here, we describe functional domains in preschoolers and assess deficits in children with ADHD problems, by comparing them to preschoolers with other mental health problems or who develop typically.

Methods: The ADHD Study assessed 1195 ca. 3.5 years old preschoolers through a semi-structured parent interview, parent questionnaires, and with neuropsychological tests. We determined functional domains by applying factor analytic methods to a broad set of questionnaire- and test-scales. Using resulting factor scores, we employed a Bayesian hierarchical regression to estimate functional deficits in children with ADHD.

Results: We found that preschoolers'functioning could be described along the seven relatively independent dimensions activity level and regulation, executive function, cognition, language, emotion regulation, introversion, and sociability. Compared to typically developing preschoolers, those with ADHD had deficits in all domains except introversion and sociability. Only deficits in activity level regulation and executive functions were larger than 0.5 standardised mean deviations and larger than deficits of children with other mental health problems.
\end{abstract}

Conclusions: Preschoolers with ADHD have deficits in multiple functional domains, but only impairments in activity level and regulation and executive functions are specific for ADHD and large enough to be clinically significant. Research on functioning in these domains will be important for understanding the development of ADHD, and for improving treatment and prevention approaches.

Keywords: ADHD, Activity level, Cognition, Affect, Emotion, Social, RDoC, Impairment, Anxiety, Behaviour problems, language problems, Functions

Attention Deficit Hyperactivity Disorder (ADHD) is a neurodevelopmental disorder characterized by symptoms of inattention, impulsivity, and hyperactivity [1], which is associated with deficits in a number of functional domains, including cognition, language, and social behaviour [2-5]. Whereas there is a general agreement

*Correspondence: guido.biele@fhi.no

${ }^{1}$ Norwegian Institute of Public Health, Oslo, Norway

Full list of author information is available at the end of the article that children with ADHD have difficulties in several domains, the relative strength and specificity of functional deficits in different domains remains unclear, especially in early childhood.

The terms function and functioning are broadly used when describing characteristics of patients with psychiatric disorders. However, their definition can vary depending on the context. The current Diagnostic and Statistical Manual of Mental Disorders (DSM-5 [6]) prescribes assessment of functioning in the domains 
Cognition, Mobility, Self-care, Getting along, Life activities and Participation. The DSM-5 also defines five neurocognitive domains for the diagnosis of neurocognitive disorders [7], which are closer to how functional domains are described in basic research about ADHD $[8,9]$. For this article, we define functional domains as groups of mental processes that are more closely related to each other than to mental processes from other domains.

Motivated by overlapping characteristics of patients with different DSM diagnoses, and by the limited success of identifying clear and distinct (biological) causes and mechanisms underlying distinct DSM diagnostic groups, functional domains have also been proposed to play an important role to further the understanding of mental disorders. The Research Domain Criteria framework (RDoC, [10]) was proposed to understand and explain mental health disorders as a combination of deficits across the domains negative valence systems, positive valence systems, cognitive systems, systems for social processes, and arousal/regulatory systems. Because many ADHD characteristics are thought to be extreme expressions of traits present in the general population, a dimensional approach should be useful for understanding ADHD [11, 12]. The RDoC approach appears particularly relevant for ADHD, because $\mathrm{RDoC}$ domains map well onto (biological) functions that are thought to be a cause of ADHD (e.g., reinforcement learning as part of the positive valence systems), functions where key ADHD symptoms are expressed (e.g., attention as part of the cognitive systems and hyperactivity as dependent on the arousal/ regulatory systems), or functions that are often impaired in ADHD (behavior problems as part of the social systems). While researchers have investigated either neuropsychological profiles (e.g., [13-15]) or temperamental aspects of ADHD [16], there is a lack of ADHD research that examines psychological functioning across a broad range of domains by using both neuropsychological tests and temperament questionnaires. Moreover, even though early functional deficits likely play an important role in the development of ADHD symptoms, there is to date litthe research on functional profiles of preschoolers.

Hence, we propose to use results from a broad range of instruments, including neuropsychological and performance tasks and parent-questionnaires about cognitive functioning and temperament (personality traits) to identify functional domains. We chose this range of measures, because both performance-based and temperamental traits can contribute to mental health problems $[13,16]$. More generally, temperamental and performance-based traits of individuals are relatively stable over time and correlated with each other [17]. Because temperamental and performance-based traits are associated with each other and ADHD, both are important for understanding ADHD and its development.

The ADHD Study, a sub-study of the Norwegian Mother and Child Birth Cohort Study (MoBa, [18]), documented functional deficits in language, executive functions, affect and emotion regulation and social behaviour in preschoolers with ADHD [19-24]. While these studies demonstrate functional deficits in preschoolers with $\mathrm{ADHD}$ and related disorders in a number of domains, the picture remains incomplete. It is unclear if these domains are independent, if deficits compared to typically developing children are equally large in all domains, and which deficits are especially strong in ADHD compared to preschool age children with other mental health or developmental problems. Lastly, the inherent uncertainty of mental health diagnoses in preschoolers [25] raises the question if children who fulfill diagnostic criteria for symptoms and impairments have different functional profiles than children who only fulfill symptom criteria.

Hence, the aim of this article is to describe functional domains in preschoolers, and to explore how functional profiles of preschoolers with ADHD problems differ from profiles of children with other mental health problems and typically developing controls. Because the instruments used in examining ADHD are oriented towards key symptoms and impairments and because RDoC domains are highly relevant for $\mathrm{ADHD}$, we hypothesize that the broad set of measures collected in the ADHD study is organized in domains similar to those described in the RDoC approach. We further hypothesize that preschoolers with ADHD have the greatest impairments in domains that are related to core ADHD symptoms.

\section{Methods}

\section{Study design and recruitment of participants}

The Norwegian Mother and Child Cohort Study (MoBa) is an ongoing prospective population-based cohort study of Norwegian-speaking women that is conducted by the Norwegian Institute of Public Health [18]. The current article is from a clinical sub-study on ADHD, for which Fig. S1 shows the recruitment procedure. This study oversampled children at risk for ADHD, by using data from the MoBa questionnaire that was administered to mothers at child age 3 years [26]. The questionnaire included 11 items about ADHD, including six items from the Child Behavior Checklist/1.5-5 (CBCL, [27]) and five items from the DSM-IV-TR criteria for ADHD [28]. Children were identified as at risk for ADHD when their sum score from the 11 ADHD symptom questions was at or above the 90th percentile of sum-scores. The cutoff was determined based on sum scores from children in MoBa born before 2004, and applied as criteria for selection into the ADHD study for children born 
April 1. 2004 and onward. Children were also identified as at risk when the mother indicated "Hyperactivity" on a list, when asked if the child "suffered any long-term illness or health problems since the age of 18 months". In addition to 2801 preschoolers at risk for ADHD, 651 control participants were invited to participate. In total, about 35\% agreed to participate in the ADHD Study, and from 2007 to 2011, 1195 children (mean age: 3.5 years, age range: 3.1 to 3.8 years) took part in a 1-day clinical assessment.

\section{Material}

The study used the semi-structured clinical parent-interview "Preschool Age Psychiatric Assessment" (PAPA, [29]) to assess mental health symptoms. The PAPA interview elicits, based on DSM IV diagnostic classifications, information about symptoms and impairments for many mental health disorders of the childhood. This includes ADHD, conduct disorder, oppositional defiant disorder and anxiety disorders. In the ADHD study, only symptoms lasting longer than 3 months from their onset were counted as present. The ADHD Study modified the PAPA by adding a section about impairments for each mental health problem (details in the supplementary materials). As an inter-rater reliability check, a separate rater who was blind to the parent and teacher screen ratings re-scored audiotapes of 79 randomly selected assessment interviews. The average intra-class correlations (ICCs) were .97 for HI symptoms, .99 for IA symptoms, and .98 for the total number of ADHD symptoms.

The ADHD Study employed a number of instruments used for diagnosis of ADHD or to assess psycho-social functions that are generally thought to be associated with ADHD. To investigate functioning, we used only parent questionnaires and tests developed to assess psychosocial functions.

This research used data from following parent questionnaires: The Behavior Rating Inventory of Executive Function-preschool version (BRIEF-P, [30, 31]) assesses functional deficits on the sub-scales inhibit, shift, emotional control, working memory and plan and organize. From the language section of the Child Development Inventory (CDI, [32, 33]) we used 50 items to score expressive language. The Children's Behavior Questionnaire $(\mathrm{CBQ},[34])$ is a temperament questionnaire with 50 items grouped into the sub-scales activity level, anger, attention focusing, discomfort, fear, high intensity pleasure, low intensity pleasure, impulsivity, inhibitory control, perceptual sensitivity, sadness and soothability. The Emotionality, Activity and Shyness temperament questionnaire (EAS, $[35,36])$ uses 12 items to score preschoolers on the sub-scales activity, emotion, shyness and sociability.
The ADHD Study used a sub-set of the NEuroPSYchological Assessment Battery tests (NEPSY, [37, 38]), including those to assess inhibition, visual attention, visuospatial processing and language. The Norwegian version of the Boston Naming Test (BNT, [39]) assess expressive language. From the Stanford-Binet Intelligence Scales 5th ed. [40] the ADHD study used the Verbal Memory for Sentences test (VMS) as an indicator of verbal working memory, the Delayed Response task/Block Span test (DR/BS) as an indicator of nonverbal working memory, the Object series, Pattern analysis/Matrices tests (OS/ PAM) as an indicator of nonverbal IQ and the Comprehension/Vocabulary test $(\mathrm{CM})$ as an indicator for verbal $I Q$. Finally, the ADHD study used a version of the Cookie Delay Task (CDT) to assess delay aversion. Because the ADHD Study was planned before the proposal of RDoC, the questionnaires and tests used in ADHD Study do not cover all $\mathrm{RDoC}$ domains equally well. In particular, the instruments employed do not allow a reliable characterization of the positive valence system. See the supplementary information for further details about the instruments and assignment of instruments to RDoC domains.

\section{Procedure}

Parents who had consented to participate received questionnaires around 4 weeks before the assessment day. For the clinical assessment, all participants travelled to Oslo University Hospital. At the assessment day, clinical psychologists or psychiatrist conducted neuropsychological tests and medical examinations in dedicated rooms. Trained graduate students in psychology conducted the PAPA parent interview under supervision of clinical experts. The assessment day concluded with a debriefing for parents. The present study was approved by the Norwegian Regional Ethics Committee for Medical and Health related Research. All procedures were performed in accordance with relevant guidelines.

\section{Data analysis}

All analyses were performed with R [41] or Mplus [42]. The supplementary information contains additional analysis details.

\section{Classification of participants into problem groups}

Classifications were determined by an algorithm that applied DSM IV symptom and impairment criteria to PAPA data. Children were classified as having ADHD, behavioural (Oppositional Defiant or Conduct Disorder) or anxiety (Social, Separation, or Generalized Anxiety, Phobia) problems with impairment, if they fulfilled DSM IV symptom and impairment criteria. They were classified as having problems without impairment, if they fulfilled only symptom criteria. We also used clinicians' 
global evaluation of the presence and impairing nature of language problems. Preschoolers who had multiple but only one impairing problem, were classified based on this problem. Children with multiple impairing problems were classified into the first of the following problem-groups for which they fulfilled diagnostic criteria: 1. ADHD, 2. behaviour, 3. anxiety, and 4. language problems. Problems-groups are ordered such that those with typically more co-morbid disorders and impairments are ranked higher. Children without a mental health problem were categorized as typically developing. (See also Fig. S3 and S4.)

\section{Choice and scoring of tests and scales}

We included scales and tests that measure psychological functioning and for which data from at least $70 \%$ of the children was available. These are the abbreviated subscales of the Stanford Binet test, NEPSY, CDT, BNT, the language section of the $\mathrm{CDI}$ and all sub-scales from the BRIEF-P, CBQ, EAS questionnaires. All tests except the BNT were scored based on the published test manuals. The BNT and questionnaire sub-scales were scored by estimating Rasch Item Response Theory (IRT) models [43] for each sub-scale of a questionnaire. We used IRT models because these use the available data better, and because estimation of latent difficulties with the same mean and standard deviation across scales facilitates the further analysis with factor-analytic methods.

\section{Identification of functional domains through exploratory structural equation modelling}

This step used test- and trait-scores calculated in the previous step. An initial analysis used a confirmatory factor analysis to examine if a theory-based assignment of scales to RDoC domains fitted the data well (see supplementary materials for the assignment of sub-scales to $\mathrm{RDoC}$ dimensions). For the data driven identification of functional domains we estimated exploratory structural equation models (ESEM). Lastly, we used CFA to explore if the model structure of the best ESEM factor model could be simplified by setting weak cross loadings to zero. Factor scores from the final model capture individual functioning in the different domains and were basis for further analyses.

\section{Comparison of functioning across functional domains and groups}

We employed a Bayesian hierarchical linear regression model to examine associations of mental health problems and functioning in all domains simultaneously, while also taking into account that associations might vary across gender and groups with different problems and degrees of impairment. By estimating the model in a Bayesian framework with weakly informative priors, one can reliably estimate variation in effect sizes between groups, and automatically control the multiple comparison problem [44]. Consistent with recent recommendations about statistical practice $[45,46]$ we report effect size means and the $90 \%$ credible intervals instead of p-values. To communicate the probability of clinically significant impairments or differences between groups, we report posterior probabilities that a difference is larger than 0.5 standardised mean differences (SMD).

\section{The study sample}

Parents of $40 \%$ of at risk for ADHD and $25 \%$ of control children consented to participate. Altogether 1195 children participated in the assessment, of which 1184 children had less than $50 \%$ of missing data on tests and scales of interest. Of these participants, 219 fullfiled DSM IV ADHD symptom criteria (168 with and 51 without impairment) Table 1 describes the study sample. Even though the sample was obtained by screening for children with ADHD symptoms and inclusion of a smaller number of random controls, most of the participants did not qualify for an ADHD diagnosis or any other child mental disorder diagnosis.

\section{Results}

\section{Dimensions of functioning}

Initial CFAs, for which sub-scales were on theoretical grounds assigned to RDoC domains, did not describe the data sufficiently well (see Table S1). The final ESEM analysis showed that a 7-factor model was the simplest model

Table 1 Study Sample

\begin{tabular}{|c|c|c|c|c|}
\hline & $T D C$ & w/impairm. & w/o impairm. & Total \\
\hline \multicolumn{5}{|c|}{ Diagnostic group } \\
\hline ADHD & - & $168(62 \%)$ & $51(29 \%)$ & $219(18.5 \%)$ \\
\hline $\mathrm{BEH}$ & - & $42(15.5 \%)$ & $25(14.2 \%)$ & $67(5.7 \%)$ \\
\hline ANX & - & $37(13.7 \%)$ & $37(21 \%)$ & $74(6.2 \%)$ \\
\hline LNG & - & $24(8.9 \%)$ & $63(35.8 \%)$ & $87(7.3 \%)$ \\
\hline TDC & 737 (100\%) & - & - & $737(62.2 \%)$ \\
\hline \multicolumn{5}{|l|}{ Gender } \\
\hline boy & $353(47.9 \%)$ & $154(56.8 \%)$ & $111(63.1 \%)$ & $618(52.2 \%)$ \\
\hline girl & $384(52.1 \%)$ & $117(43.2 \%)$ & $65(36.9 \%)$ & $566(47.8 \%)$ \\
\hline \multicolumn{5}{|l|}{ Age (months) } \\
\hline Mean (SD) & $41.7(1.3)$ & $41.7(1.3)$ & $41.7(1.3)$ & $41.7(1.3)$ \\
\hline \multicolumn{5}{|c|}{ Maternal education } \\
\hline Elem., HS & $161(22.2 \%)$ & $105(39.5 \%)$ & $60(34.5 \%)$ & $326(28 \%)$ \\
\hline Bachelor & $330(45.5 \%)$ & $101(38 \%)$ & $66(37.9 \%)$ & $497(42.7 \%)$ \\
\hline Master & $234(32.3 \%)$ & $60(22.6 \%)$ & $48(27.6 \%)$ & $342(29.4 \%)$ \\
\hline
\end{tabular}

Note. Fig. $\mathrm{S} 2$ shows all observed combinations of mental health problems $A N X$ anxiety, $B E H$ behaviour problems, LNG language problems 
that could adequately describe the data (RMSEA $=0.03$ $(0.028,0.037), \mathrm{CFI}=0.96)$. Because follow up CFA analyses that constrained small cross-loadings to zero resulted in unsatisfactory RMSEA and CFI statistics, we retained the final ESEM model as the best model of functional domains.

Table S2 and Fig. S5 show the factor loadings from the best ESEM model. This suggests following factors: activity level and regulation (AL, the ability to down-regulate physical activity), executive functions (EF, the ability to regulate behaviour and cognitive functions), cognition (CO, working memory and cognitive flexibility), language (LA), emotion regulation (ER, the ability to control emotions), introversion (IN, the preference for calm activities) and sociability (SO, the ability to get into contact with others). The average of the unsigned factor correlations was 0.15. Following factor correlations were larger than $0.30: \mathrm{r}(\mathrm{LA}, \mathrm{CO})=0.39, \mathrm{r}(\mathrm{EF}, \mathrm{AL})=0.32, \mathrm{r}(\mathrm{ER}, \mathrm{EF})=0.32$ (c.f. Table S3).

\section{Functional profiles of preschoolers with ADHD problems} Across all domains, functioning of preschoolers with ADHD was -0.42 standardised mean differences (SMD) below the functioning of typically developing preschoolers. The average SMDs for preschoolers with ADHD with and without impairment were -0.55 and -0.30 , respectively. Preschoolers with language problems had functioning deficits similar to preschoolers with ADHD, whereas children with behaviour or anxiety problems had milder deficits (c.f. Table S4). Figure 1 and Table 2 show functional profiles. Preschoolers with ADHD were particularly impaired in the domains EF and $\mathrm{AL}$, where their functioning was around -0.90 SMD below that of typically developing controls $(P(S M D<-0.5)=1)$. In comparison, functioning levels of preschoolers with ADHD in the domains CO, LA and ER was only around -0.50 SMD below typically developing controls $(P(S M D<-0.5)=0.56)$. Functioning in the domains SO and IN did not differ substantially from typically developing controls (average $\mathrm{SMD}=0 ; P(S M D<-0.5)=0$ ). Preschoolers with ADHD with and without impairment had similar functioning patterns. However, with exception of the domains $\mathrm{CO}$ and SO, those with impairment had around 0.30 SMD larger deficits than those without. We found overall small gender differences. Only in SO did boys with ADHD show somewhat weaker deficits than girls.

Figure 2 and Tables 2 and S7 report comparisons between preschoolers with ADHD and those with other mental health or developmental problems. Only deficits in $\mathrm{AL}$ (with impairment: $\mathrm{SMD}=-1.04 \quad(-1.23$, -0.86 ; $\mathrm{P}(\mathrm{SMD}<-.5)=1.00)$, without impairment: $\mathrm{SMD}=-0.74 \quad(-0.98, \quad-0.49 ; \quad \mathrm{P}(\mathrm{SMD}<-.5)=0.94))$ and $\mathrm{EF}$ (with impairment: $\mathrm{SMD}=-0.61 \quad(-0.79$, $-0.42 ; \quad \mathrm{P}(\mathrm{SMD}<-.5)=0.84))$, without impairment: $\mathrm{SMD}=-0.35 \quad(-0.59, \quad-0.11 ; \quad \mathrm{P}(\mathrm{SMD}<-.5)=0.15))$ were larger in preschoolers with ADHD, compared to preschoolers with other mental health problems. Preschoolers with ADHD had only moderately more difficulties in $\mathrm{CO}$ (with impairment: $\mathrm{SMD}=-0.32(-0.50$, $-0.13 ; \quad \mathrm{P}(\mathrm{SMD}<-.5)=0.05)$, without impairment: $\mathrm{SMD}=-0.24(-0.48,-0.01 ; \mathrm{P}(\mathrm{SMD}<-.5)=0.04))$ compared to preschoolers with other mental health problems, and similar or fewer difficulties in the domains LA, ER, IN, or SO (with impairment: $\mathrm{SMD}=0.14$ $(0.04, \quad 0.25 ; \quad \mathrm{P}(\mathrm{SMD}<-.5)=0.00))$, without impairment: $\mathrm{SMD}=0.28 \quad(0.15, \quad 0.41 ; \mathrm{P}(\mathrm{SMD}<-.5)=0.00))$. In particular, children with ADHD had much weaker LA deficits than preschoolers with impairing language problems (with impairment: $\mathrm{SMD}=1.20(0.89$, 1.53; $\mathrm{P}(\mathrm{SMD}<-.5)=0.00)$, without impairment: $\mathrm{SMD}=0.86(0.58,1.14 ; \mathrm{P}(\mathrm{SMD}<-.5)=0.00))$, and were more sociable than children with impairing anxiety problems (with impairment: $\mathrm{SMD}=1.12(0.87,1.38$; $\mathrm{P}(\mathrm{SMD}<-.5)=0.00)$, without impairment: $\mathrm{SMD}=0.82$ $(0.52,1.13 ; \mathrm{P}(\mathrm{SMD}<-.5)=0.00))$. Figure 3 summarises the comparisons and highlights that, whereas preschoolers with ADHD are impaired compared to TDC in most functional domains, only impairments of $\mathrm{AL}$ and $\mathrm{EF}$ are specific to ADHD in that they are larger than 0.5 SMD compared to TDC and also larger than deficits of preschoolers with other mental health problems. See Table S6 for more details.

\section{Discussion}

The aim of the current study was to describe domains of functioning in preschoolers and to compare functioning of preschoolers with ADHD problems with that of preschoolers with other or no problems. We identified seven weakly correlated functional domains: Executive functioning (EF), activity level and regulation (AL), cognition $(\mathrm{CO})$, language (LA), introversion (IN), emotion regulation (ER) and sociability (SO). Compared to typically developing children, functional deficits of preschoolers with ADHD were especially pronounced in AL and $\mathrm{EF}$, less pronounced in $\mathrm{CO}, \mathrm{LA}$, and $\mathrm{ER}$, and absent in SO and IN. Compared to children with anxiety, behaviour or language problems, children with ADHD had similar or weaker deficits in all domains except AL and EF, where they had substantially greater impairments. Therefore, only EF and AL impairments appear specific to children with ADHD problems.

A likely reason for divergences between our and the $\mathrm{RDoC}$ domains is that the set of instruments used influences which domains a study recovers. The use of many instruments to assess language and cognition 


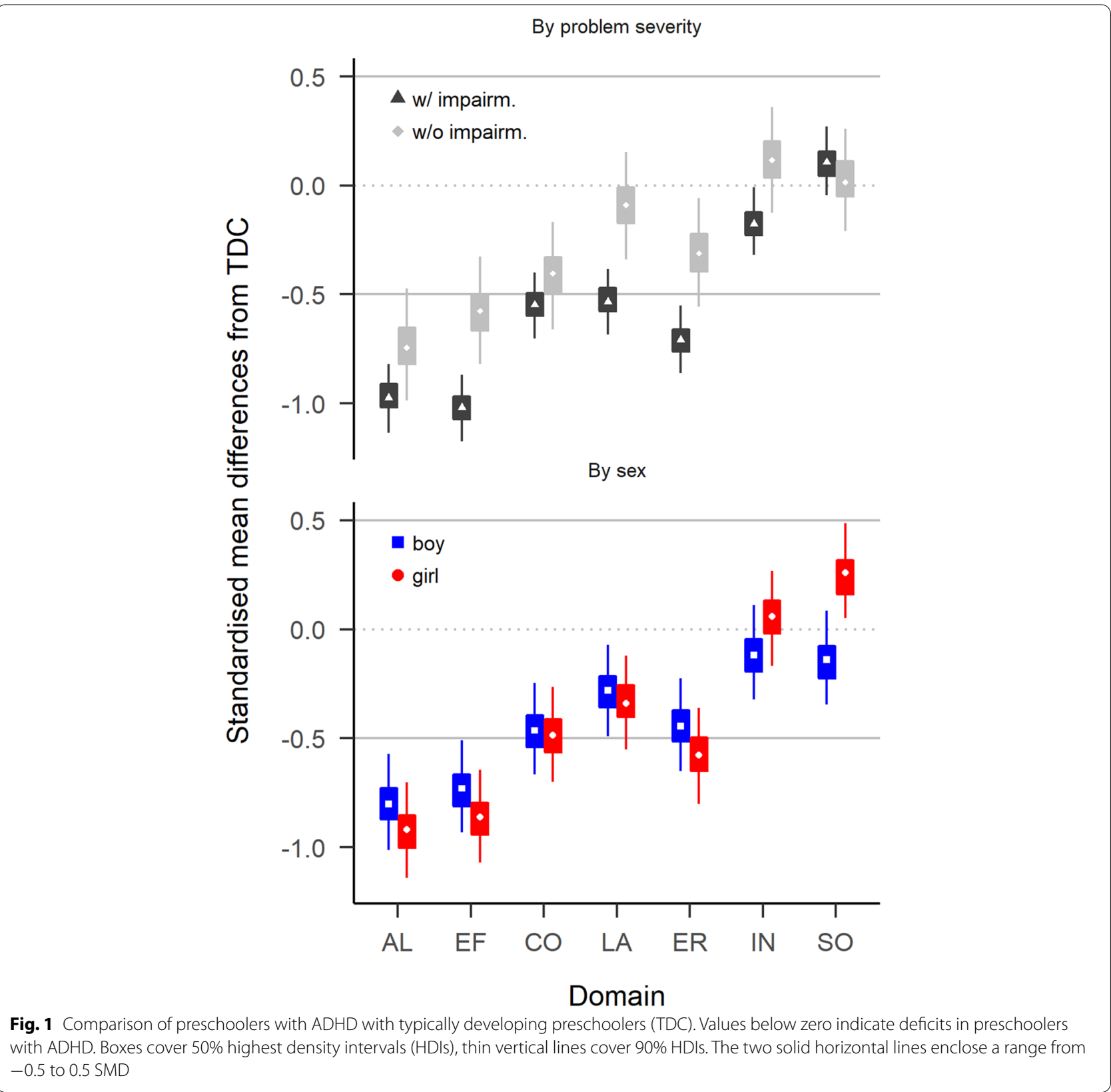

Table 2 Differences in functioning between preschoolers with ADHD and preschoolers with no or other problems

\begin{tabular}{lllll}
\hline Domain & TDC vs ADHD w/ impairm & TDC vs ADHD w/o impairm & TDC vs All ADHD & Other MHP vs All ADHD \\
\hline AL & $-0.97(-1.14,-0.82 ; 1.00)$ & $-0.74(-0.99,-0.47 ; 0.97)$ & $-0.92(-1.07,-0.78 ; 1.00)$ & $-0.89(-1.41,-0.37 ; 0.88)$ \\
EF & $-1.02(-1.17,-0.87 ; 1.00)$ & $-0.58(-0.82,-0.33 ; 0.74)$ & $-0.91(-1.04,-0.77 ; 1.00)$ & $-0.48(-0.92,-0.07 ; 0.44)$ \\
CO & $-0.55(-0.70,-0.40 ; 0.73)$ & $-0.40(-0.66,-0.17 ; 0.22)$ & $-0.51(-0.65,-0.37 ; 0.58)$ & $-0.28(-0.81,0.32 ; 0.28)$ \\
LA & $-0.53(-0.68,-0.38 ; 0.67)$ & $-0.09(-0.34,0.15 ; 0.00)$ & $-0.43(-0.55,-0.28 ; 0.16)$ & $0.36(-0.41,1.31 ; 0.02)$ \\
ER & $-0.71(-0.86,-0.55 ; 0.99)$ & $-0.31(-0.56,-0.06 ; 0.07)$ & $-0.62(-0.75,-0.47 ; 0.95)$ & $-0.12(-0.62,0.33 ; 0.1)$ \\
IN & $-0.18(-0.32,-0.01 ; 0.00)$ & $0.12(-0.13,0.36 ; 0.00)$ & $-0.11(-0.24,0.04 ; 0.00)$ & $0.14(-0.34,0.58 ; 0.01)$ \\
SO & $0.11(-0.05,0.27 ; 0.00)$ & $0.02(-0.21,0.26 ; 0.00)$ & $0.09(-0.07,0.22 ; 0.00)$ & $0.47(-0.06,1.21 ; 0)$ \\
\hline
\end{tabular}

Values are mean (lower, upper 90\% HDI; $\mathrm{P}(\mathrm{SMD}<-0.5)$ ). See main text for abreviations LA - SO 


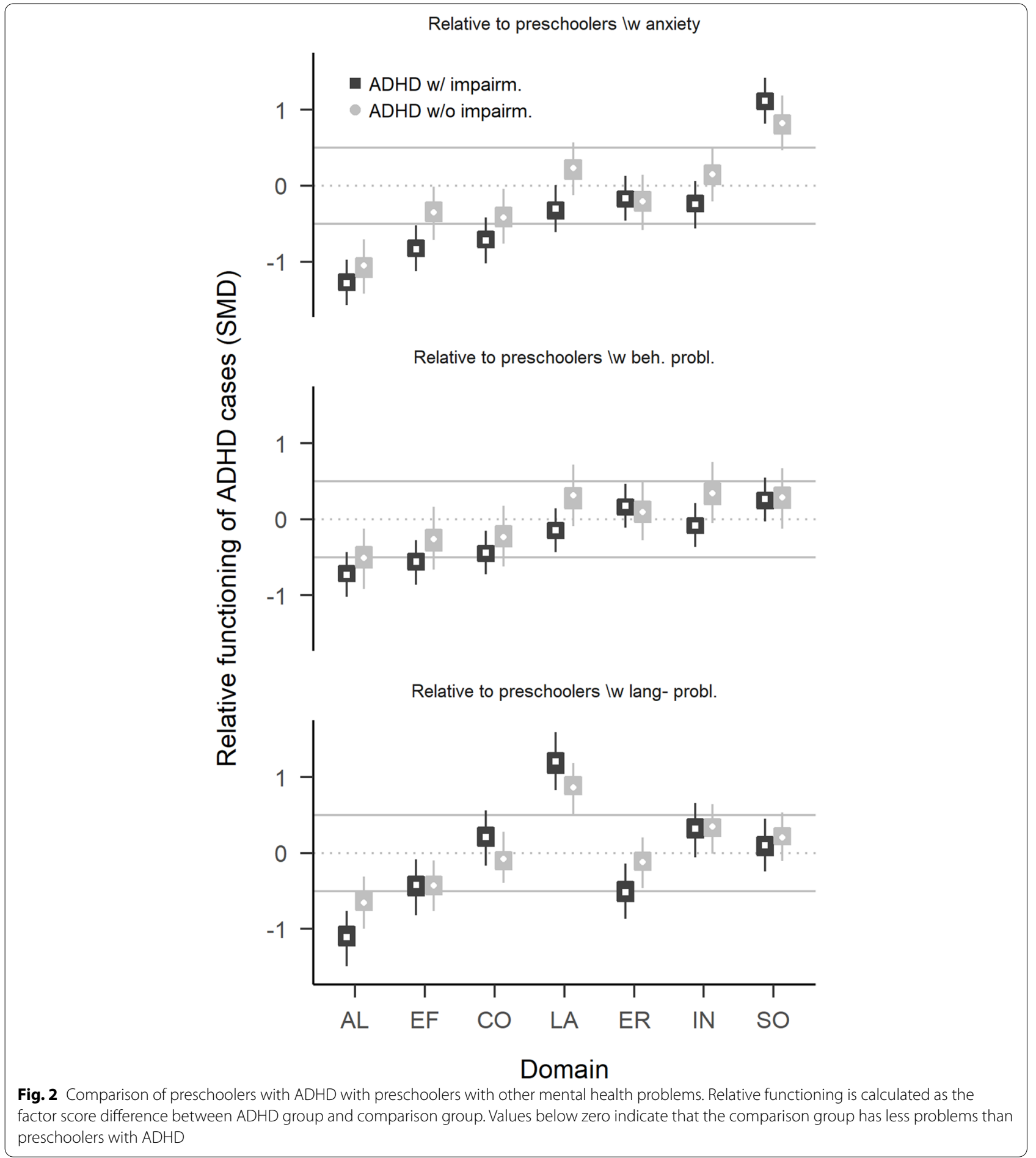

likely contributed to our identification of two domains in this area, whereas the sparse assessment of reward processing likely impeded us from identifying such a domain or even specific concepts within reward processing like reinforcement learning of delay aversion.
In sum, while the domains we identified are broadly consistent with the RDoC domains, we cannot make a confident statement in favour of or against RDoC domains, because the study was not designed to test the RDoC domains. 


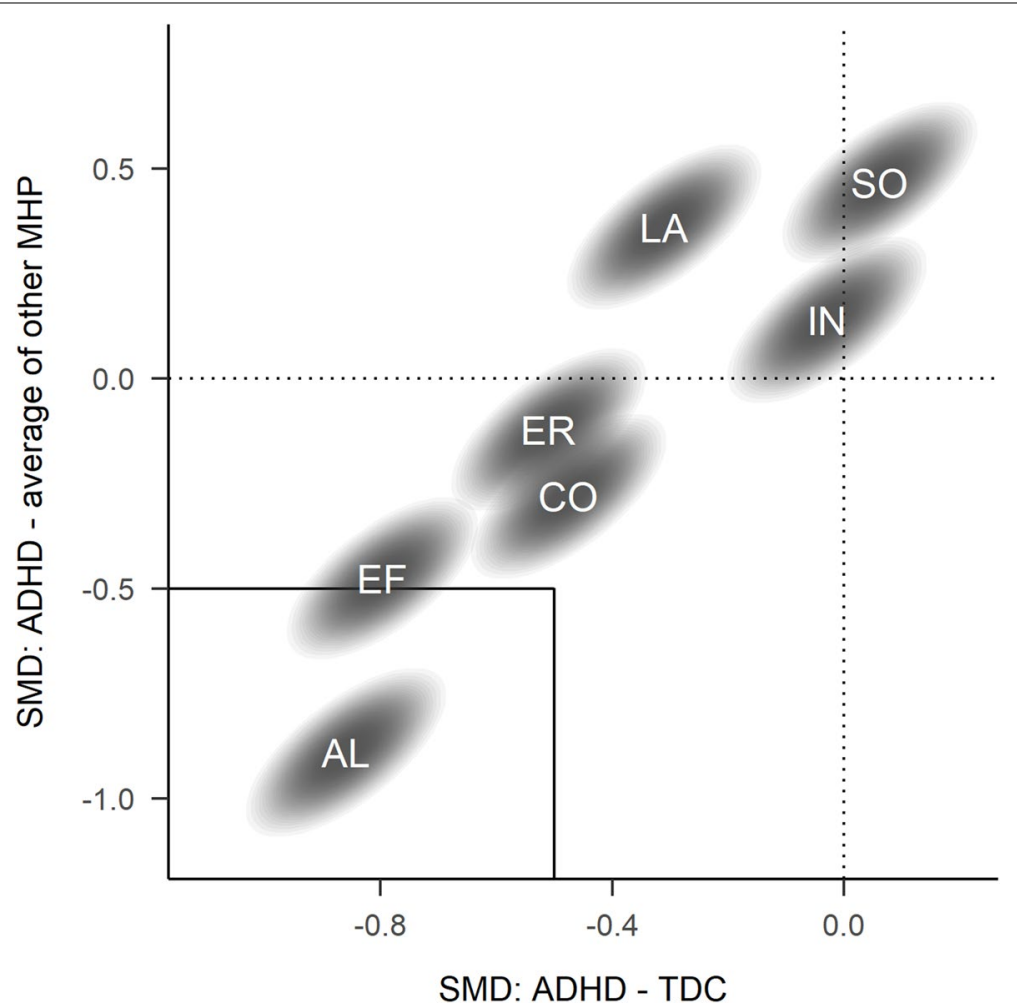

Fig. 3 Joint comparison of factor scores differences between preschoolers with ADHD and typically developing preschoolers (TDC, on the $x$-axis) and those with other mental health problems (MHP, on the $y$-axis). Differences are averaged across preschoolers with and without impairment. Values below zero indicate that preschoolers with ADHD have stronger problems than the comparison group. Ellipses cover $90 \%$ highest density intervals. Labels in ellipses indicate functional domains. Domains in the lower left rectangle are those where preschoolers with ADHD have a 0.5 SMD larger deficit compared to TDC and children with other MHPs. See Fig. S10 for comparisons with specific other MHPs

Similar to earlier investigation, we observed only small correlations between assessments of the same construct with parent-questionnaires and tests. Toplak, West and Stanovich [47] hypothesized that the low correlation could be explained by the fact that tests primarily measure the ability to perform a task, whereas questionnaires in addition measure the ability to independently focus energy in a goal-oriented manner. This interpretation assumes that both instrument types reliably measure traits and abilities. The low correlations could also be due to unsystematic and systematic errors in both instrument types. For example, tests can measure state in addition to trait, and questionnaires suffer from response biases or varying understanding of parents about what behaviour is normative. Repeated administration of tests would provide the most reliable information and should if possible be used in the assessment of children.

As expected, we found the largest deficits of children with ADHD in the domains of activity level and regulation and executive functions. The prominence of EF and AL impairments is consistent with a dual pathways view of the development of $\mathrm{ADHD}$, which suggests that ADHD can be caused by earlier functional deficits [48]. While the original formulation of the dual pathway hypothesis highlights deficits in EF and reward processing as key causes for the development of ADHD symptoms, we only find direct evidence for early EF deficits, likely due to the sparse assessment of reward processing in the ADHD study with a CDT task and CBQ scales about high- and low-intensity pressure, but without a more detailed assessment of, e.g., reinforcement learning. Still, our results provide indirect evidence for the hypothesis of early reward processing deficits, if one considers that some ADHD theories suggest that a heightened activity level is an indicator for impaired reward processing [2, 49]. Still, future studies should put more emphasis on the assessment of reward processing in early childhood, in order to improve the understanding of its role in the development of ADHD symptoms. The prominence of $\mathrm{AL}$ and EF deficits in early childhood raises the likelihood that they are causes of later deficits in the other domains. 
While the broadness of functions investigated in the ADHD Study and the large sample size set this study apart, some aspects of the study suggest caution when generalizing results to the broader population. The sample composition, which is characterized by self-selection into the study based on high parental education, high parental ratings of preschool ADHD symptoms, and absence of children with ASD (which were recruited into a sister study on ASD, [50]), does not fully reflect the population of preschoolers with ADHD problems. Regarding the absences of children with ASD, additional comparisons based on the $\mathrm{ABC}$ study sample shown in the supplementary materials (Fig. S11 and following) suggest that the differences between children with and without ADHD we found are not unique to the ADHD Study sample. Still, given the sample characteristics, the presented results generalize most readily to a population of preschoolers who are at risk to develop ADHD and who have relatively well-educated parents.

The current study is of exploratory nature and reports only cross-sectional associations between different functional domains. Nevertheless, the presented results suggest that because impairments in $\mathrm{AL}$ and $\mathrm{EF}$ are much stronger and central than other deficits, first choice treatment of preschoolers with ADHD from populations similar to the study sample should focus on these areas, because other functional deficits will typically be less severe. Future research on cross-lagged associations between functioning in different domains (c.f [51]) is needed to investigate the causal role of EF and AL for later development, and to inform if focus of treatment in these domains is indicated.

In sum, the current study identified functional domains similar to, but not identical with the RDoC framework. Preschoolers with ADHD have deficits in most functional domains, but only deficits in activity level and regulation and executive functions were clinically significant $(\mathrm{SMD}>0.5)$ and more expressed in preschoolers with ADHD compared to those with other problems. Future longitudinal research on the development of functioning in domains over time will be important to investigate a causal role of early functional deficits in the development of ADHD, and for the further development of effective early interventions for ADHD.

\section{Supplementary Information}

The online version contains supplementary material available at https://doi. org/10.1186/s12888-021-03638-9.

Additional file 1.

\section{Acknowledgements}

The Norwegian Mother, Father and Child Cohort Study is supported by the Norwegian Ministry of Health and Care Services and the Ministry of Education and Research. We are grateful to all the participating families in Norway who take part in this on-going cohort study.

\section{Authors' contributions}

All authors conceived of the study. GB analysed the data and wrote the manuscript. All authors finalized the manuscript. The author(s) read and approved the final manuscript.

\section{Funding}

This research was supported by a grant of the ADHD Research Network in Norway.

\section{Availability of data and materials}

The dataset supporting the conclusions of this article is available upon application to Norwegian Mother, Father and Child Cohort Study (MoBa, https:// www.fhi.no/en/studies/moba/.

\section{Declarations}

\section{Ethics approval and consent to participate}

Informed consent was acquired from all participants. The research was approved by the Regional Ethics Committee of Norway - South-East. All procedures performed were in accordance with the ethical standards of the institutional and/or national research committee and with the 1964 Helsinki Declaration and its later amendments.

\section{Consent for publication}

Not applicable.

\section{Competing interests}

The authors have no competing interests.

\section{Author details}

${ }^{1}$ Norwegian Institute of Public Health, Oslo, Norway. ${ }^{2}$ Oslo University Hospital, Oslo, Norway.

Received: 23 March 2021 Accepted: 30 November 2021

Published online: 01 February 2022

\section{References}

1. Thapar A, Cooper M. Attention deficit hyperactivity disorder. Lancet. 2016;378:1240-50

2. Ziegler S, Pedersen ML, Mowinckel AM, Biele G. Modelling ADHD: a review of ADHD theories through their predictions for computational models of decision-making and reinforcement learning. Neurosci Biobehav Rev. 2016:71:633-56.

3. Larson K, Russ SA, Kahn RS, Halfon N. Patterns of comorbidity, functioning, and service use for US children with ADHD, 2007. Pediatrics. 2011;127:462-70.

4. Willcutt E, Sonuga-Barke E, Nigg J, Sergeant J. Recent developments in neuropsychological models of childhood psychiatric disorders. In: Biological Child Psychiatry Karger Publishers; 2008. p. 195-226.

5. Rommel AS, Rijsdijk F, Greven CU, Asherson P, Kuntsi J. A longitudinal twin study of the direction of effects between ADHD symptoms and IQ. PLoS One. 2015;10:e0124357.

6. American Psychiatric Association. Diagnostic and statistical manual of mental disorders: DSM-5. 5th ed. Washington, DC: American Psychiatric Association; 2013.

7. Sachdev PS, Blacker D, Blazer DG, Ganguli M, Jeste DV, Paulsen JS, et al. Classifying neurocognitive disorders: the DSM-5 approach. Nat Rev Neurol. 2014;10:634-42.

8. Nikolas MA, Nigg JT. Neuropsychological performance and attentiondeficit hyperactivity disorder subtypes and symptom dimensions. Neuropsychology. 2013;27:107-20. 
9. Mueller A, Hong DS, Shepard S, Moore T. Linking ADHD to the neural circuitry of attention. Trends Cogn Sci. 2017;21:474-88.

10. Insel T, Cuthbert B, Garvey M, Heinssen R, Pine DS, Quinn K, et al. Research domain criteria (RDoC): toward a new classification framework for research on mental disorders. Am J Psychiatry. 2010;167:748-51.

11. Baroni A, Castellanos FX. Neuroanatomic and cognitive abnormalities inattention-deficit/hyperactivity disorder in the era of 'high definition' neuroimaging. Curr Opin Neurobiol. 2015;30:1-8.

12. Doyle AE. Commentary: insights from across diagnostic boundaries: ADHD in the RDoC era-a commentary on Scerif and baker (2015). J Child Psychol Psychiatry Allied Discip. 2015;56:274-7.

13. Fair DA, Bathula D, Nikolas MA, Nigg JT. Distinct neuropsychological subgroups in typically developing youth inform heterogeneity in children with ADHD. Proc Natl Acad Sci U S A. 2012;109:6769-74.

14. van Hulst BM, de Zeeuw P, Durston S. Distinct neuropsychological profiles within ADHD: a latent class analysis of cognitive control, reward sensitivity and timing. Psychol Med. 2015;45:735-45.

15. Lambek R, Sonuga-Barke E, Tannock R, Sørensen AV, Damm D, Thomsen $\mathrm{PH}$. Are there distinct cognitive and motivational sub-groups of children with ADHD? Psychol Med. 2018:48:1722-30.

16. Karalunas SL, Fair DA, Musser ED, Aykes K, lyer SP, Nigg JT. Subtyping attention-deficit/hyperactivity disorder using temperament dimensions: toward biologically based nosologic criteria. JAMA Psychiatry. 2014;71:1015-24.

17. Ackerman PL, Heggestad ED. Intelligence, personality, and interests: evidence for overlapping traits. Psychol Bull. 1997;121:219-45.

18. Magnus P, Irgens LM, Haug K, Nystad W, Skjaerven R, Stoltenberg C, et al. Cohort profile: the Norwegian mother and child cohort study (MoBa). Int J Epidemiol. 2006;35:1146-50.

19. Rohrer-Baumgartner N, Zeiner P, Eadie P, Egeland J, Gustavson K, Reichborn-Kjennerud T, et al. Language delay in 3-year-old children with ADHD symptoms. J Atten Disord. 2016;20:867-78.

20. Skogan AH, Zeiner P, Egeland J, Rohrer-Baumgartner N, Urnes A-G, Reichborn-Kjennerud T, et al. Inhibition and working memory in young preschool children with symptoms of ADHD and/or oppositional-defiant disorder. Child Neuropsychol. 2014;20:607-24.

21. Skogan AH, Zeiner P, Egeland J, Urnes A-G, Reichborn-Kjennerud T, Aase $H$. Parent ratings of executive function in young preschool children with symptoms of attention-deficit/-hyperactivity disorder. Behav Brain Funct. 2015;11:16

22. Overgaard KR, Oerbeck B, Aase H, Torgersen S, Reichborn-Kjennerud T, Zeiner P. Emotional Lability in preschoolers with symptoms of ADHD. $J$ Atten Disord. 2018;22:787-95.

23. Overgaard KR, Aase H, Torgersen S, Zeiner P. Co-occurrence of ADHD and anxiety in preschool children. J Atten Disord. 2016;20:573-80.

24. Bendiksen B, Svensson E, Aase H, Reichborn-Kjennerud T, Friis S, Myhre $\mathrm{AM}$, et al. Co-occurrence of ODD and CD in preschool children with symptoms of ADHD. J Atten Disord. 2017;21:741-52.

25. McClellan JM, Speltz ML. Psychiatric diagnosis in preschool children. J Am Acad Child Adolesc Psychiatry. 2003;42:127-8 author reply 128-30.

26. Overgaard KR, Aase H, Torgersen S, Reichborn-Kjennerud T, Oerbeck B, Myhre A, et al. Continuity in features of anxiety and attention deficit/ hyperactivity disorder in young preschool children. Eur Child Adolesc Psychiatry. 2014;23:743-52.

27. Achenbach T, Rescorla L. ASEBA preschool forms \& profiles: an integrated system of multi-informant assessment. Burlington: University of Vermont Department of Psychiatry; 2000.

28. American Psychiatric Association. Diagnostic and statistical manual of mental disorders (4th ed., Text Revision). Washington, DC: American Psychiatric Association; 2000.

29. Egger HL, Angold A. The preschool age psychiatric assessment (PAPA): a structured parent interview for diagnosing psychiatric disorders in preschool children. In: DelCarmen-Wiggins R, editor. Handbook of infant, toddler, and preschool mental health assessment. New York: Oxford University Press, xiv; 2004. p. 223-43.

30. Gioia GA, Isquith PK, Retzlaff PD, Espy KA. Confirmatory factor analysis of the behavior rating inventory of executive function (BRIEF) in a clinical sample. Child Neuropsychol. 2002;8:249-57.

31. Gioia GA, Isquith PK, Retzlaff PD, Espy KA. Behavior rating inventory of executive function preschool version. Norwegian manual supplement. Lutz: Psychological Assessment Resources; 2007.
32. Ireton $\mathrm{H}$, Glascoe FP. Child development inventory manual. Mn: Behavior Science Systems, Inc.; 1992.

33. Ireton H, Glascoe FP. Assessing children's development using parents' reports. Child Dev Invent Clin Pediatr. 1995;34:248-55.

34. Putnam SP, Rothbart MK. Development of short and very short forms of the Children's behavior questionnaire. J Pers Assess. 2006;87:102-12.

35. Buss AH, Plomin R. Temperament: early developing personality traits: Psychology Press; 1984.

36. Mathiesen KS, Tambs K. The EAS temperament questionnaire-factor structure, age trends, reliability, and stability in a Norwegian sample. J Child Psychol Psychiatry Allied Discip. 1999;40:431-9.

37. Korkman M, Kemp S, Kirk U. NEPSY: A developmental neuropsychological assessment. San Antonio: The Psychological Corporation; 1998.

38. Korkman M, Kemp S, Kirk U. NEPSY. Handbok [Handbook]. Stockholm: Psykologiforlaget AB; 2000.

39. Kaplan E, Goodglass H, Weintraub S, Brand S. Boston naming test. Philadelphia: Lea \& Febiger; 1983.

40. Roid GH. Stanford Binet intelligence scales; 2003.

41. R Core Team. R. A language and environment for statistical computing. Vienna: R Foundation for Statistical Computing; 2019.

42. Muthen LK, Muthen BO. Mplus User's Guide. 8th ed. Los Angeles: Muthen \& Muthen; 2017.

43. Rasch G. Probabilistic models for some intelligence and attainment tests. Philadelphia: MESA Press; 1960.

44. Gelman A, Hill J, Yajima M. Why we (usually) Don't have to worry about multiple comparisons. J Res Educ Effect. 2012;5:189-211.

45. Sullivan GM, Feinn R. Using effect size-or why the P value is not enough. J Grad Med Educ. 2012;4:279-82.

46. Wasserstein RL, Schirm AL, Lazar NA. Moving to a World Beyond " $p<0.05$ ". Am Stat. 2019;73:1-9.

47. Toplak ME, West RF, Stanovich KE. Practitioner review: do performancebased measures and ratings of executive function assess the same construct? J Child Psychol Psychiatry Allied Discip. 2013;54:131-43.

48. Sonuga-Barke EJS. The dual pathway model of AD/HD: an elaboration of neuro-developmental characteristics. Neurosci Biobehav Rev. 2003;27:593-604

49. Sagvolden T, Johansen EB, Aase H, Russell VA. A dynamic developmental theory of attention-deficit/hyperactivity disorder (ADHD) predominantly hyperactive/impulsive and combined subtypes. Behav Brain Sci. 2005;28:397-419 discussion 419-68.

50. Stoltenberg C, Schjolberg S, Bresnahan M, Hornig M, Hirtz D, Dahl C, et al. The autism birth cohort: a paradigm for gene-environment-timing research. Mol Psychiatry. 2010;15:676-80.

51. Arnett AB, Pennington BF, Willcutt E, Dmitrieva J, Byrne B, Samuelsson $S$, et al. A cross-lagged model of the development of ADHD inattention symptoms and rapid naming speed. J Abnorm Child Psychol. 2012:40:1313-26.

\section{Publisher's Note}

Springer Nature remains neutral with regard to jurisdictional claims in published maps and institutional affiliations.

Ready to submit your research? Choose BMC and benefit from:

- fast, convenient online submission

- thorough peer review by experienced researchers in your field

- rapid publication on acceptance

- support for research data, including large and complex data types

- gold Open Access which fosters wider collaboration and increased citations

- maximum visibility for your research: over $100 \mathrm{M}$ website views per year

At $\mathrm{BMC}$, research is always in progress.

Learn more biomedcentral.com/submissions 